\title{
Main determinants of physical activity levels in individuals with Parkinson's disease
}

\author{
Fatores determinantes do nível de atividade física de indivíduos com doença de Parkinson \\ Raquel de Carvalho Lana', Lysandra Nogueira de Araujo², Francisco Cardoso, Fátima Rodrigues-de-Paula²
}

\begin{abstract}
This study analyzed the relationship between patient characteristics, factors associated with Parkinson's disease (PD), and physical activity level of individuals affected by the disease. Forty-six volunteers with mild-to-moderate idiopathic PD were assessed using sections II/III of the Unified Parkinson's Disease Rating Scale and their motor functions were classified according to the modified Hoehn and Yahr (HY) scale. Data such as age, disease duration, the Human Activity Profile (HAP), the Fatigue Severity Scale were collected. Lower limb bradykinesia and clinical subtypes of PD were defined. Two models that explained $76 \%$ of the variance of the HAP were used. The first comprised age, ability to perform activities of daily living (ADL), and the HY scale; the second comprised age, ability to perform ADL, and lower limb bradykinesia. Possible modifiable factors such as the ability to perform ADL and lower limb bradykinesia were identified as predictors of physical activity level of individuals with PD.
\end{abstract}

Keywords: Parkinson's disease, physical activity, bradykinesia, fatigue.

RESUMO

Este estudo analisou a relação entre características dos pacientes, fatores associados com a doença de Parkinson (DP) e nível de atividade física de indivíduos afetados pela doença. Quarenta e seis voluntários com DP leve a moderada foram avaliados usando a Escala de Avaliação Unificada da Doença de Parkinson (UPDRS), e classificados de acordo com a Escala de Hoehn e Yahr modificada (HY). Dados como idade, duração da doença, Perfil de Atividade Humana (PAH), Escala da Severidade da Fatiga (FSS) foram coletados. Bradicinesia de membros inferiores e subtipos clínicos foram definidos. Dois modelos que explicaram $76 \%$ da variância do PAH foram observados. 0 primeiro compreende idade, habilidade de realizar Atividades de Vida Diária (AVD) e a escala de HY modificada; e o segundo compreende idade, habilidade de realizar AVD, e bradicinesia. Fatores modificáveis como a habilidade de realizar AVD e bradicinesia foram identificados como preditores do nível de atividade física de indivíduos com DP.

Palavras-chave: doença de Parkinson, atividade física, bradicinesia, fadiga.

Parkinson's disease (PD) is a chronic and degenerative disease of the central nervous system characterized by a combination of motor and non-motor disorders ${ }^{1}$. PD may severely compromise the ability to perform tasks such as walking, writing, turning, and moving in bed ${ }^{1}$, mainly because of a combination of motor limitations, fatigue, and apathy ${ }^{2}$. The progression of PD is associated with progressive deficits, which might contribute to sedentarism, and result in reduced physical ability in these patients ${ }^{3}$.

A recent study indicated that individuals with PD are $29 \%$ less active than healthy individuals ${ }^{2}$. However, the ability of patients in the initial phase of PD to perform physical exercise may be comparable to that of healthy individuals when they maintain a certain level of regular physical activity. Although the daily pattern of physical activity in the initial phase of the disease appears similar to that of controls ${ }^{4}$, this tends to change when PD progresses ${ }^{4}$.

Recent studies have assessed factors that might play a role in the level of physical activity of PD patients ${ }^{2,5}$. Factors related to the disease such as severity of disease, levodopa daily dose and motor impairment level; factors related to the individual such as age and walking performance were pointed out as determinants of the physical activity level ${ }^{2,5}$. Factors such as lower limb bradykinesia, clinical subtype and fatigue,

\footnotetext{
${ }^{1}$ Universidade Federal de Minas Gerais, Programa de Pós-graduação em Ciências da Reabilitação, Belo Horizonte MG, Brazil;

${ }^{2}$ Universidade Federal de Minas Gerais, Departamento de Fisioterapia, Belo Horizonte MG, Brazil;

${ }^{3}$ Universidade Federal de Minas Gerais, Departamento de Medicina Interna, Belo Horizonte MG, Brazil.
}

Correspondence: Fátima Rodrigues-de-Paula; Departamento de Fisioterapia, Escola de Educação Física, Fisioterapia e Terapia Ocupacional da Universidade Federal de Minas Gerais; Avenida Antônio Carlos, 6627;31270-901 Belo Horizonte MG, Brasil; E-mail: fatimarp@globo.com

Conflict of interest: There is no conflict of interest to declare.

Support: Fundação de Amparo à Pesquisa do Estado de Minas Gerais (FAPEMIG), Conselho Nacional de Desenvolvimento Científico e Tecnológico (CNPq), Pró-reitoria de Pós-graduação da Universidade Federal de Minas Gerais (UFMG).

Received 31 October 2014; Received in final form 20 September 2015; Accepted 13 October 2015. 
that may decrease the level of physical activity in individuals with PD, have not yet been studied.

It is known that inactivity is considered a risk factor for several diseases and may worsen various motor and non-motor symptoms that are affected in $\mathrm{PD}^{2}$. Additionally, previous studies have explained only up to $28 \%$ of the variance of the level of physical activity of these individuals ${ }^{2,5}$. Knowledge of the factors that affect the level of physical activity of individuals with PD may guide clinicians that work with PD rehabilitation, and thereby prevent inactivity and its consequences. Therefore, the aim of the present study was to analyze factors associated with the disease (progression time, severity, clinical subtype, and lower limb bradykinesia) and the individual (age, ability to perform daily living activities, and fatigue) that may predict or explain the variance in the level of physical activity of individuals with PD.

\section{METHOD}

\section{Participants}

This was a cross-sectional study in which the participants were recruited by convenience from the University's Outpatient Clinic for Movement Disorders. Participants were recruited by students and evaluated by a trained researcher. Individuals with idiopathic PD, diagnosed by a neurologist specialized in movement disorders, according to the UK Brain Bank criteria ${ }^{6}$, classified as a score of 1-4 on the modified Hoehn and Yahr (HY) disability scale, using antiparkinsonian medication, and who did not show other neurological, musculoskeletal, or cardiovascular disorders were included in the analysis. All participants were briefed on the objectives of the research, and then they signed a free and informed consent form. This study was approved by the Ethics in Research Committee of the university.

\section{Measures}

\section{Identification and characterization}

The study participants were subjected to an initial evaluation for data collection, which included questions regarding identification, age, medication use, progression of the disease, and associated pathologies.

\section{Clinical evaluation and questionnaires}

To evaluate the severity of the disease, activities of daily living (ADL) and motor sections of the Unified Parkinson's Disease Rating Scale (UPDRS) and the modified HY scale were used $^{7.8}$. The bradykinesia score from the lower limbs was calculated using the sum of the scores of items 26,27 , 29, and 31 of the UPDRS. The higher scores of those items indicated increased severity of bradykinesia9. The clinical subtypes of PD were classified as tremor-dominant (T), rigidakinetic (RA), and mixed (M) according to the classification proposed by Schiess et al. ${ }^{10}$. The perception of fatigue was assessed using the Fatigue Severity Scale (FSS), and the level of physical activity was determined using the Human Activity Profile (HAP). The HAP was adapted and validated to portuguese (Brazil) $)^{11}$ and comprises 94 items of routine activities with different functional levels, and can classify individuals as inactive, moderately active, or active $\mathrm{e}^{11,12}$.

\section{Procedures}

The initial evaluation for the collection of data was performed through an interview and an identification form. The participants were informed about the aims of the study, and the eligible individuals were subjected to a clinical functional evaluation using the partial UPDRS and the modified HY scale. Next, the level of physical activity of the participants was evaluated by a trained examiner using the HAP questionnaire. Subsequently, subjects were classified into PD subtypes, and the lower limb bradykinesia score was calculated. Lastly, the FSS was applied to classify the subjects' fatigue levels.

\section{Statistical analysis}

All analyses were performed using $R$ version 2.13 .0 software, and descriptive statistics was carried out for all the investigated variables. First, simple linear regression analysis was conducted to verify the relationships between the HAP as a dependent variable and the various independent variables (age, PD progression time, UPDRS-motor score, UPDRS-ADL score, modified HY stage, clinical subtypes, lower limb bradykinesia, and fatigue). Next, multiple linear regression analyses were performed, using forward selection for the variables. In the first step, it was included in the model the variable which explained most the variance in the univariate regression, provided it was significant for a significance level of 0.05 . In the following step, an additional variable was added, provided it resulted in a better fit (in terms of explained variance) compared to the other still not included variables and that all variables in the model remain significant. Similar steps followed until the point in which the inclusion of any other variable would not result in a model with all independent variables statistically significant.

\section{RESULTS}

A total of 46 individuals with PD participated in this study, including 29 men and 17 women, with a mean age of $65.9 \pm 12.1$ years (range, $42-88$ years). The mean time of disease progression was $11.1 \pm 7.4$ years (range, $2-38$ years). One (2\%), 4 (9\%), 21 (46\%), 6 (13\%), 9 (19\%), and 5 (11\%) individuals were classified as stage 1, 1.5, 2, 2.5, 3, and 4 according to the modified HY scale, respectively. Regarding the clinical subtypes of PD, twenty-four (52\%) patients were classified as RA, $12(26 \%)$ as T, and $10(22 \%)$ as M. Furthermore, $56.5 \%$ of 
the participants showed significant fatigue. According to the HAP score, $50 \%$ of the individuals were classified as active, $19.6 \%$ as moderately active, and $30.4 \%$ as inactive.

The FSS, UPDRS-ADL, UPDRS-motor, and HAP scores are shown in Table 1. The results from the univariate linear regression analysis are shown in Table 2. Age, PD progression time, modified HY stage, UPDRS-ADL, UPDRS-motor, lower limb bradykinesia, and fatigue all showed significant associations with the HAP score.

Two models were proposed by the multiple linear regression analysis. The results of these proposed models are shown in Tables 3 and 4. In the first model, age, UPDRS-ADL score, and modified HY stage were found to explain $76 \%$ of the variance of the HAP score. In the second model, age, UPDRS-ADL score, and lower limb bradykinesia were found to also explain $76 \%$ of the HAP score variance.

\section{DISCUSSION}

We proposed two models to explain the variance in the level of physical activity in individuals with PD, because it would be impossible to statistically define which variable, namely disease severity or lower limb bradykinesia would best predict the level of physical activity in such individuals. The two models were able to predict $76 \%$ of the variance in the level of physical activity, as evaluated by the HAP.

Although few studies have assessed factors affecting physical activity level of individuals with PD, some authors have indicated factors associated with the disease and/or the individual. Nimwegen et al. ${ }^{2}$ observed that a higher severity of the disease, walking deficits, and an inability to perform ADL predicted $24 \%$ of the variance of the patients' daily physical activity level. Our results also indicated the inability to perform $\mathrm{ADL}$ and disease severity as predictors of the level of physical activity in individuals with PD. However, after adding these factors to age, a higher percentage of this variance was explained (76\%).

Furthermore, in a recent study, age, levodopa daily dose, distance covered in the 6-min walk test, and the total UPDRS score were found to predict only $28 \%$ of the daily physical activity level in sedentary PD patients ${ }^{5}$. As in this previous study, we found that age was a determinant of the level of physical activity. Increased age was associated with increased progression of motor impairment; decreased responsiveness to levodopa treatment; and more severe postural, walking, and cognitive deficits in patients with $\mathrm{PD}^{13,14,15}$. The strong influence of age on the physical activity level and the non-influence of disease duration, as observed in this study, have been pointed out by many authors ${ }^{15,16}$. Thus, the decrease in the physical activity level seems to be highly associated with the immobility and sedentarism of older individuals ${ }^{16}$, since the aging process by itself is characterized by a decline in the physical ability and functional performance ${ }^{17}$.
Table 1. Scores obtained in the evaluations performed in the study $(n=46)$.

\begin{tabular}{lcc}
\hline Test & $\begin{array}{c}\text { Mean } \\
\text { (standard deviation) }\end{array}$ & Range \\
\hline FSS & $4(2.1)$ & $1-7$ \\
UPDRS-ADL & $31.3(17.4)$ & $0-52$ \\
UPDRS-MOTOR & $14.2(8.8)$ & $0-108$ \\
HAP & $63.8(24.2)$ & $0-94$ \\
\hline FSS: Fatigue Severity Scale; UPDRS: Unified Parkinson's Disease Rating \\
Scale; ADL: activities of daily living; HAP: Human Activity Profile.
\end{tabular}

Table 2. Coefficients of univariate regression.

\begin{tabular}{lcc}
\hline Variable & $\begin{array}{c}\text { Regression } \\
\text { coefficient }\end{array}$ & $\begin{array}{c}95 \% \text { confidence } \\
\text { interval }\end{array}$ \\
\hline Age & -1.08 & $(-1.58,-0.59)^{\star}$ \\
PD time & $-1,37$ & $(-2.25,-0.48)^{\star}$ \\
HY & -23.24 & $(-30.04,-16.44)^{\star}$ \\
UPDRS-ADL & -2.01 & $(-2.57,-1.45)^{\star}$ \\
UPDRS-MOTOR & -0.89 & $(-1.21,-0.57)^{\star}$ \\
RA & -9.91 & $(-23.77,3.94)$ \\
Tremor & 4.35 & $(-11.70,20.41)$ \\
Bradykinesia & -3.77 & $(-4.80,-2.74)^{\star}$ \\
Fatigue & -4.80 & $(-7.86,-1.73)^{\star}$ \\
\hline PD time: Parkinson's disease progression time; HY: Hoehn and Yahr disability \\
stages; UPDRS: Unified Parkinson's Disease Rating Scale; ADL: activities of \\
daily living; RA: rigid-akinetic. *Significant relationship $(p<0.05)$ between the \\
variables and the physical activity level (HAP).
\end{tabular}

Table 3. Coefficients of regression and $95 \%$ confidence intervals $(95 \% \mathrm{Cl})$ of the multivariate regression analysis, with inclusion of HY stage.

\begin{tabular}{lcc}
\hline Variable & $\begin{array}{c}\text { Regression } \\
\text { coefficient }\end{array}$ & $95 \% \mathrm{Cl}$ \\
\hline Age & -0.81 & $(-1.11,-0.51)^{\star}$ \\
UPDRS-ADL & -1.20 & $(-1.78,-0.62)^{\star}$ \\
HY & $-10,30$ & $(-17.24,-3.36)^{\star}$ \\
Intercept & 159.28 & \\
$\mathrm{R}^{2}$ & 0.76 & \\
\hline
\end{tabular}

Regression equation: $Y=159.28-0.81 \mathrm{Xi}-1.20 \mathrm{Xu}-10.30 \mathrm{Xh}$.

With $\mathrm{Xi}=$ age; $\mathrm{Xu}=$ UPDRS-ADL; and Xh = HY.

UPDRS: Unified Parkinson's Disease Rating Scale; ADL: activities of daily living; HY: Hoehn and Yahr disability stages; $R^{2}$ : Explained variance. ${ }^{*} p<0.05$.

Table 4. Regression coefficients and $95 \% \mathrm{Cl}$ of the multivariate regression analysis, with inclusion of lower limb bradykinesia.

\begin{tabular}{lcc}
\hline Variable & $\begin{array}{c}\text { Regression } \\
\text { coefficient }\end{array}$ & $95 \% \mathrm{Cl}$ \\
\hline Age & -0.81 & $(-1.11,-0.50)^{\star}$ \\
UPDRS-ADL & -1.10 & $(-1.75,-0.45)^{\star}$ \\
Lower limb bradykinesia & -1.72 & $(-2.94,-0.50)^{\star}$ \\
Intercept & 144.03 & \\
$\mathrm{R}^{2}$ & 0.76 & \\
\hline
\end{tabular}

Regression equation: $Y=144.03-0,81 \mathrm{Xi}-1.10 \mathrm{Xu}-1.72 \mathrm{Xb}$.

With $\mathrm{Xi}=$ age; $\mathrm{Xu}=$ UPDRS-ADL; and $\mathrm{Xb}=$ bradykinesia.

UPDRS: Unified Parkinson's Disease Rating Scale;ADL: activities of daily living;

$\mathrm{R}^{2}$ : Explained variance. ${ }^{\star} \mathrm{p}<0.05$ 
The ability to perform ADL was found to be a predictive factor for the level of physical activity in patients with PD, as previously reported ${ }^{2}$. A higher loss of functional independence was associated with a higher UPDRS score and a more severe disease as per the modified HY scale, indicating a positive association between disease severity and the need for help in ADL and instrumental activities ${ }^{18}$.

Disease severity was found to be a predictive factor of the physical activity level in such individuals in other previous studies $^{2,5}$. Unlike the results of our study, previous studies ${ }^{2,5}$ noted that the total UPDRS score alone or along with the HY stage were predictive factors of the level of physical activity in PD patients. The HY scale has been widely used for the clinical evaluation of PD patients, and describes categories of motor dysfunction. High correlations have been reported between $\mathrm{HY}$ progression and motor decline and deterioration of quality of life in individuals with PD, confirming its wide use in the classification of PD severity ${ }^{8}$.

To our knowledge, ours is the first study to identify that lower limb bradykinesia is a predictive factor of the level of physical activity in patients with PD. Bradykinesia is considered the most debilitating symptom of the disease and is associated with reduced ability of the patient to perform various functional tasks ${ }^{1}$. In addition, an interaction effect between the duration of the disease and age on bradykinesia has been previously reported ${ }^{15}$. This indicates that the simultaneous effects of age and disease duration on bradykinesia are not additive, as they are highly dependent on each other. Various clinical scores, including the UPDRS-motor score, have been reported to show stronger associations with velocity than with amplitude of movement ${ }^{19}$. Despite the complex relation between these factors, these previous findings, as well as the findings from this study, indicate that lower limb bradykinesia is associated with motor deficits, age, and disease progression.

For the definition of bradykinesia, we used the subscore proposed by Allen et al. ${ }^{9}$. In fact, it is a lower limb bradykinesia subscore derived by summing items of the UPDRS motor examination. As many studies used the same subscore, it allowed us to make comparisons between them ${ }^{9,19}$. Besides that, most of the activities of the HAP (more than 75\%) involve mainly the lower limbs.

To our knowledge, this was the first study assessing subtype classification as a possible predictive factor of the level of physical activity of patients with PD. Although the clinical heterogeneity among patients with PD has been extensively debated ${ }^{7}$, indicating the existence of clinical subtypes of the disease, this classification remains controversial and requires a better definition. Accordingly, several authors have proposed different subtype classifications ${ }^{10,20,21}$, although a clear and accepted classification has not yet been established. This indefinition may have influenced with the findings of the present study, and this requires further investigation.

Finally, fatigue was not a predictive factor of the physical activity level in individuals with PD. It is known that the physiologic stress of daily physical activities is increased in patients with PD, and this may contribute to the elevated level of fatigue that is characteristic of the disease ${ }^{22}$. Thus, we expected that fatigue would influence the physical activity level of such individuals. However, the relationship between fatigue and the measures of physical activity is intriguing. Garber and Friedman ${ }^{23}$ observed that a higher degree of fatigue was associated with a low level of physical activity. It is evident that patients with increased fatigue move less, but it is uncertain whether fatigue is the cause of physical inactivity or if it is the result of a sedentary lifestyle ${ }^{23}$. According to Elbers et al. ${ }^{24}$ the variance in the physical activity level explained by fatigue is small (only 2\%). These findings, as well as those from our study, suggest that fatigue may be an independent symptom of PD that cannot predict the level of physical activity and that may only represent a minor factor within the numerous factors that affect the level of physical activity in individuals with PD.

The findings of our study indicate that the level of physical activity is in part explained by factors that cannot be modified, such as age, but also by factors modifiable by therapeutic intervention, such as ability to perform ADL and lower limb bradykinesia.

Based on our results, bradykinesia and the identification of difficulties in performing ADL must be target during physical therapy evaluation, particularly when these factors are present in older individuals with PD. Therefore, rehabilitation programs should include functional training of activities and gain of speed, which could make such individuals more physically active and reduce the adverse consequences of inactivity.

Our study has some limitations. Although most activities related to the physical activity level involve the lower limbs, upper limb bradykinesia was not evaluated. Moreover, although no significant difficulty has been observed during the tests, cognition was not formally evaluated in all participants. Most importantly, we were unable to identify which variable (modified HY stage or lower limb bradykinesia) better predicted the level of physical activity in patients with PD. This was likely due to a strong association between then, with both reflecting disease severity, making it difficult to define which variable is the best predictor in this study, considering the relatively small sample size. This interaction may also have occurred due to the methodological bias between the scales itself. The bradykinesia measure is derived from four questions of the motor UPDRS, which reflects disease severity, such as the HY scale.

In conclusion, up to $76 \%$ of the variance in the physical activity level of individuals with PD can be explained by age, the ability to perform ADL, and the severity of the disease (as determined by the modified HY scale), or by lower limb bradykinesia. In contrast to the expected result, the UPDRS-motor score, disease progression time, clinical subtypes of the disease, and fatigue did not explain this variance. According to our results, factors that can be modified by therapeutic intervention were identified and they must be evaluated and considered when proposing rehabilitation programs for PD. 
1. Morris ME. Movement disorders in people with Parkinson disease: $\mathrm{a}$ model for physical therapy. Phys Ther. 2000;80(6):578-97.

2. Nimwegen M, Speelman AD, Hofman-van Rossum EJM, Overeem S, Deeg DJH, Borm GF et al. Physical inactivity in Parkinson's disease. J Neurol. 2011;258(12):2214-21. doi:10.1007/s00415-011-6097-7

3. Canning CG, Alison JA, Allen NE, Groeller H. Parkinson's disease: an investigation of exercise capacity, respiration function, and gait. Arch Phys Med.Rehabil. 1997;78(2):199-207. doi:10.1016/S0003-9993(97)90264-1

4. Hilten JJ, Hoogland G, Velde EA, Middelkoop HA, Kerkhof GA, Roos RA. Diurnal effects of motor activity and fatigue in Parkinson's disease. J Neurol Neurosurg Psychiatry. 1993;56(8):874-7. doi:10.1136/jnnp.56.8.874

5. Dontje ML, Greef M, Speelman A,Ninwegen M, Krijnen WP, Stolk R. Determinants of daily physical activity in inactive Parkinson's disease patients. J Sci Med Sport. 2013;15:S34-126. doi:10.1016/j.jsams.2012.11.190

6. Hughes AJ, Daniel SE, Kilford L, Lees AJ. Accuracy of clinical diagnosis of idiopathic Parkinson's disease:a clinico-pathological study of 100 cases.J Neurol Neurosurg Psychiatry. 1992;55(3):181-4. doi:10.1136/jnnp.55.3.181

7. Schenkman ML, Clark K, Xie T, Kuchibhatla M, Shinberg M, Ray L. Spinal movement and performance of a standing reach task in participants with and without Parkinson disease. Phys Ther. 2001;81(8):1400-11.

8. Goetz CG, Poewe W, Rascol O, Sampaio C, Stebbins GT, Giladi N et al. Movement Disorder Society Task Force report on the Hoehn and Yahr staging scale: status and recommendations. Mov Disord. 2004;19(8):1020-8. doi:10.1002/mds.20213

9. Allen NE, Canning CG, Sherrington C, Fung VSC. Bradykinesia, muscle weakness and reduced muscle power in Parkinson's disease. Mov Disord. 2009;24(9):1344-51. doi:10.1002/mds.22609

10. Schiess MC, Zheng H, Soukup VM, Bonnen JG, Nauta HJW. Parkinson's disease subtypes: clinical classification and ventricular cerebrospinal fluid analysis. Parkinsonism Relat Disord. 2000;6(2):69-76. doi:10.1016/S1353-8020(99)00051-6

11. Souza AC, Magalhães LC, Teixeira-Salmela LF. Adaptação transcultural e análise das propriedades psicométricas da versão brasileira do Perfil de Atividade Humana. Cad Saúde Pública. 2006;22(12):2623-36. doi:10.1590/S0102-311X2006001200012

12. Davidson M, Morton N. A systematic review of the Human Activity Profile. Clin Rehabil. 2007;21(2):151-62. doi:10.1177/0269215506069475
13. Lee CS, Schulzer M, Mak EK, Snow BJ, Tsui JK, Clane S et al. Clinical observations on the rate of progression of idiopathic parkinsonism. Brain. 1994;117(3):501-7. doi:10.1093/brain/117.3.501

14. Levy G, Louis ED, Cote L, Perez M, Mejia-Santana H, Andrews $\mathrm{H}$ et al. Contribution of aging to the severity of different motor signs in Parkinson Disease. Arch Neurol. 2005;62(3):467-72. doi:10.1001/archneur.62.3.467

15. Levy G. The relationship of Parkinson disease with aging. Arch Neurol. 2007;64(9):1242-6. doi:10.1001/archneur.64.9.1242

16. Potter JM, Evans SAL, Duncan G. Gait speed and activities of daily living function in geriatric patients. Arch Phys Med Rehabil. 1995;76(11):997-9. doi:10.1016/S0003-9993(95)81036-6

17. Matsudo SM, Matsudo VKR. Prescrição e benefícios da atividade física na terceira idade. Rev Bras Ciênc Mov. 1992;6(4):19-30.

18. Shulman LM, Gruber-Baldini AL, Anderson KE, Vaughan CG, Reich SG, Fishman PS et al. The evolution of disability in Parkinson disease. Mov Disord. 2008;23(6):790-6. doi:10.1002/mds.21879

19. Kim JW, Kwon Y, Kim YM, Chung HY, Ecom GM, Jun JH et al. Analysis of lower limb bradykinesia in Parkinson's disease patients. Geriatr Gerontol Int. 2012;12(2):257-64. doi:10.1111/j.1447-0594.2011.00761.x

20. Stebbins GT, Goetz CG, Bum DJ, Jankovic J, Khoo TK, Tiley BC. How to identify tremor dominant and postural instability/gait difficulty groups with the movement disorder society unified Parkinson's disease rating scale: comparison with the Unified Parkinson's Disease Rating Scale. Mov Disord. 2013;28(5):668-70. doi:10.1002/mds.25383

21. Van Rooden SM, Colas F, Martinez-Martin P, Visser M, Verbaan D, Marinus J et al. Clinical subtypes of Parkinson's disease. Mov Disord. 2011;26(1):51-8. doi:10.1002/mds.23346

22. Christiansen CL, Schenkman ML, Mc Fann K, Wolfe P, Kohrt WM. Walking economy in people with Parkinson's disease. Mov Disord. 2009;24(10):1481-7. doi:10.1002/mds.22621

23. Garber CE, Friedman JH. Effects of fatigue on physical activity and function in patients with Parkinson's disease. Neurology. 2003;60(7):1119-24. doi:10.1212/01.WNL.0000055868.06222.AB

24. Elbers R, Wegen EEH, Rochester L, Hetherington V, Nieuwboer A, Willems AM et al. Is impact of fatigue an independent factor associated with physical activity in patients with idiopathic Parkinson's disease? Mov Disord. 2009;24(10):1512-8. doi:10.1002/mds.22664 